\title{
Nematódeos de ruminantes em pastagem com diferentes sistemas de pastejo com ovinos e bovinos
}

\author{
Sônia Emília Figueiredo de Araújo Torres ${ }^{(1)}$, Concepta McManus(1), \\ Alessandro Francisco Talamini do Amarante ${ }^{(2)}$, Viviane Verdolin ${ }^{(1)}$ e Helder Louvandini(1)
}

(1)Universidade de Brasília, Faculdade de Agronomia e Medicina Veterinária, Caixa Postal 9.508, CEP 70910-970 Brasília, DF. E-mail: soniaftorres@ig.com.br, concepta@unb.br, viviane.verdolin@gmail.com, hlouvand@unb.br(2)Universidade Estadual Paulista, Instituto de Biociências, Departamento de Parasitologia, Caixa Postal 510, CEP 18618-000 Botucatu, SP. E-mail: amarante@ibb.unesp.br

Resumo - O objetivo deste trabalho foi avaliar os efeitos de diferentes sistemas de pastejo, com ovinos e bovinos, sobre a quantidade de larvas no estágio $\mathrm{L}_{3}$ de nematódeos de ruminantes. $\mathrm{O}$ delineamento experimental foi inteiramente ao acaso, em arranjo fatorial com quatro sistemas de pastejo e quatro períodos de rotação de pastagem. A duração do experimento foi de 91 dias, com sistema rotacionado (7 dias de ocupação e 21 de descanso), em 8 ha de Panicum maximum cv. Tanzânia. Foram avaliados os sistemas de pastejo: alternado, simultâneo e isolado, com ovinos e com bovinos. Foram utilizados 20 bovinos (mestiços), 30 cordeiros e 15 ovelhas adultas (raça Santa Inês). As amostras do capim, para recuperação e identificação dos nematódeos, foram realizadas semanalmente no pré e pós-pastejo dos piquetes. Na média geral de todos os manejos, a ordem decrescente de número de larvas foi: Haemonchus spp., Trichostrongylus spp., Oesophagostomum spp., Strongyloides spp. e Cooperia spp. Correlações médias foram encontradas entre as quantidades de larvas $\mathrm{L}_{3}$ no pré e pós-pastejo. Com o aumento do número de rotações, houve aumento no grau de contaminação da pastagem pelas larvas, independentemente do sistema adotado. O sistema de pastejo simultâneo foi o que apresentou maior controle da carga parasitária de Haemonchus spp. na pastagem de capimtanzânia.

Termos para indexação: Panicum maximum, forma de vida livre, nematódeo gastrintestinal.

\section{Ruminant nematodes in pasture under different grazing systems with sheep and cattle}

\begin{abstract}
The objective of this work was to evaluate the effect of different grazing management systems on the parasitic nematode load $\left(\mathrm{L}_{3}\right.$ larvae) in ruminants. The experimental design was completely randomized, in a factorial arrangement with four grazing systems and four rotations. The experimental period was 91 days, in a rotational system (7 days of occupation and 21 of days rest), in 8-ha pasture cultivated with Panicum maximum cv. Tanzânia. The different management systems evaluated were: alternate, simultaneous and isolate whit cattle and sheep. Twenty mixed breed cattle, 30 lambs and 15 ewes were used (Santa Inês breed). Grass samples were collected for recovery and identification of $\mathrm{L}_{3}$-larvae every week, during pre and postgrazing. In all systems, the decreasing order the number of identified larvae was Haemonchus spp., Trichostrongylus spp., Oesophagostomum spp., Strongyloides spp., and Cooperia spp. Mean correlations were found between $\mathrm{L}_{3}$-larvae numbers in pre and postgrazing. Increasing rotation caused increase in the degree of infection irrespectively of the system used. The simultaneous system had the best control on the parasitic load of Haemonchus spp., on Tanzania grass pasture.
\end{abstract}

Index terms: Panicum maximum, free-life form, gastrointestinal nematode.

\section{Introdução}

Os ovinos estão presentes em áreas com as mais diversas características climáticas, distribuídos em todos os continentes. No Brasil, a ovinocultura de corte encontra-se em expansão, em razão da demanda crescente do consumo da carne ovina. No entanto, para abastecer esse mercado cada vez mais exigente, os hipermercados e restaurantes especializados são obrigados a importar carne ovina principalmente do Uruguai.
O parasitismo não é sinônimo de doença, pois, geralmente, os animais de um rebanho se encontram em boas condições de saúde, mesmo com a presença de parasitos. Isto decorre do fato de os hospedeiros terem mecanismos imunológicos que possibilitam, na maioria das vezes, manter a população de endoparasitos sob controle. Nesse cenário, pode-se afirmar que a relação parasito-hospedeiro se encontra em equilíbrio (Amarante, 2001).

A administração de anti-helmínticos aos animais é a principal medida de controle adotada, para prevenir 
prejuízos causados pela verminose (Miller \& Horohov, 2006). Entretanto, uma das consequências da ampla utilização dessas drogas foi o surgimento de nematódeos resistentes, problema que se encontra disseminado nas criações de ovinos mundialmente (Jackson \& Coop, 2000; Kaplan, 2004). Com adoção de medidas estratégicas, é possível aumentar a relação custo-benefício da atividade. Em geral, os animais têm grande suscetibilidade à verminose até a puberdade. A resistência aumenta na idade adulta, porém há determinadas épocas e condições fisiológicas em que o animal fica mais suscetível (Miller \& Horohov, 2006).

Várias estratégias têm sido sugeridas para o controle dos parasitos, entre elas a alimentação adequada no atendimento à exigência nutricional do animal, o que favorece sua condição orgânica para enfrentar ameaças de doenças, principalmente, as infecções por verminose (Louvandini et al., 2006). $\mathrm{O}$ uso de alimentos ricos em taninos condensados também tem-se mostrado eficiente em alguns casos (Cenci et al., 2007).

A utilização de diferentes espécies de ruminantes em pastejo, na mesma área, pode ser uma forma de diminuir as populações de larvas de nematódeos, além de permitir o aperfeiçoamento de manejo do pasto. O manejo possibilita que as larvas das espécies que parasitam os ovinos sejam ingeridas pelos bovinos ou vice-versa, e que no hospedeiro sejam destruídas (Amarante et al., 2004). No entanto, alguns estudos mostraram que a diversidade de espécies de nematódeos foi maior quando os ovinos compartilharam pastagens com bovinos (Giudici et al., 1999).

Em razão de controvérsia de resultados e de escassa literatura científica sobre o tema, objetivou-se com este trabalho avaliar a contaminação de larvas $\left(\mathrm{L}_{3}\right)$ de nematódeos em pastagem de Panicum maximum cv. Tanzânia, em quatro diferentes sistemas de manejos de pastejo com bovinos e ovinos.

\section{Material e Métodos}

O estudo foi realizado na Fazenda Água Limpa, da Universidade de Brasília (UnB), no Distrito Federal $\left(15^{\circ} 57^{\prime} \mathrm{S}, 47^{\circ} 56^{\prime} \mathrm{W}\right.$, altitude próxima a $\left.1.000 \mathrm{~m}\right)$, onde o tipo climático é tropical estacional (AW), segundo classificação de Köppen, com estacionalidade do regime de chuvas, invernos secos e verões chuvosos, e pluviosidade anual de 1.500 a $1.900 \mathrm{~mm}$. O período experimental foi de 91 dias, de janeiro a abril de 2008, durante o período das águas.

$\mathrm{O}$ experimento foi realizado em delineamento inteiramente casualizado, em arranjo fatorial $(4 \mathrm{x} 4) \mathrm{com}$ quatro manejos de pastejo e quatro períodos de rotação do pasto, em pastagem de capim $P$. maximum cv. Tanzânia com aproximadamente 8 ha, que foi subdividida em 17 piquetes de aproximadamente 0,4 ha cada, destinados a quatro tratamentos com sistemas de pastejo distintos: alternado - primeiro os bovinos depois os ovinos; bovinos - somente com bovinos; ovinos - somente com ovinos; e simultâneo - com ovinos e bovinos.

Para os sistemas de pastejo bovinos, ovinos esimultâneo, foram utilizados quatro piquetes e, no alternado, cinco, o que permitiu a rotação da pastagem com sete dias de ocupação e 21 dias de descanso, em todos os sistemas.

Em todos os tratamentos, foi mantida a taxa de lotação de duas unidades animais (UA) ha ${ }^{-1}$, tomando-se como referência a espécie bovina (animal $450 \mathrm{~kg}$ ) e, tendo-se considerado que, em termos de consumo, cinco ovelhas adultas equivalem a uma UA bovina, segundo Carvalho \& Rodrigues (1997). Foram utilizados como animais experimentais: 20 bovinos mestiços, dos quais 13 machos e sete fêmeas, na mesma faixa etária e com peso médio de $206,70 \pm 20,79 \mathrm{~kg} ; 30$ cordeiros e 15 ovelhas adultas, da raça Santa Inês, com peso médio de $22,70 \pm 2,23 \mathrm{~kg}$ e $47,38 \pm 7,67 \mathrm{~kg}$, respectivamente. Nos sistemas alternado e simultâneo, foram utilizados 16 animais para cada tratamento, dos quais dez cordeiros e seis bovinos. No tratamento bovinos, foram utilizados oito bovinos. No tratamento ovinos, foram utilizados 10 cordeiros e 15 ovelhas adultas.

Além da pastagem, os animais receberam suplementação concentrada de 0,2 e 2,06 kg por dia por animal; para os ovinos, essa suplementação foi com $55 \%$ de milho triturado, $30 \%$ de farelo de soja, $10 \%$ de farelo de algodão e $5 \%$ de farelo de trigo; e para os bovinos, a suplementação foi com $60 \%$ de milho e $40 \%$ de farelo de soja. Os bovinos permaneceram todo o tempo nos piquetes, e os ovinos foram recolhidos diariamente, para o pernoite em abrigo fechado. $\mathrm{O}$ fornecimento de água e sal mineral foram ad libitum para ambas as espécies. Para os bovinos, a mistura mineral esteve disponível no piquete, em cochos localizados à altura inacessível aos ovinos e, para estes, o sal permanecia no abrigo. 
Antes de iniciar o período experimental, uma associação dos princípios ativos albendazol e levamisol foi utilizada, para que todos os animais fossem desverminados e mantidos confinados, até que a contagem de ovos por grama de fezes (OPG) fosse zero.

O capim foi colhido semanalmente, antes da entrada e após a saída dos animais dos piquetes. Foram colhidas quatro amostras em cada piquete, a partir de corte do capim rente ao solo, em retângulos de $0,5 \mathrm{~m}^{2}$ que, juntas, formavam uma amostra composta. Os pontos de colheita foram aleatórios dentro dos piquetes. Essa amostra composta foi colocada sobre uma lona, em que o capim foi revolvido e do qual se retiraram outras amostras, para serem processadas da seguinte forma: acondicionamento, por 4 horas, em balde com $4 \mathrm{~L}$ de água e $0,5 \mathrm{~mL}$ de detergente neutro (Extran MA 02 Neutro, Merck S.A.). Após esse tempo, a amostra foi transferida para um segundo balde, com a mesma quantidade de água e detergente neutro, onde permaneceu por mais 3 horas. Depois da lavagem, o capim foi retirado do balde, para ser colocado em estufa a $60^{\circ} \mathrm{C}$ por 72 horas, para determinação da massa de matéria seca, o que permitiu calcular o número de larvas $\mathrm{L}_{3}$ por kilograma de matéria seca. $\mathrm{O}$ conteúdo do primeiro balde foi misturado ao do segundo, tendo ficado em repouso por 24 horas. Após esse período, o sobrenadante foi sifonado, e o conteúdo restante transferido para proveta de $1 \mathrm{~L}$, onde permaneceu por mais 24 horas. Em seguida, o sobrenadante foi novamente retirado, com o auxílio de uma trompa a vácuo, e o conteúdo restante foi transferido para um cálice cônico com uma peneira e, dentro da peneira, um lenço de papel (Softy's, Melhoramentos Papéis Ltda.), para coar o material, que ficou em repouso por mais 12 horas.

Em seguida, a peneira foi retirada e o sobrenadante sifonado, tendo-se deixado uma quantidade de aproximadamente $5 \mathrm{~mL}$ no fundo do cálice, que foi transferida para um tubo cônico graduado, com capacidade de $15 \mathrm{~mL}$, com tampa de rosca, devidamente identificado e mantido sob refrigeração a $4^{\circ} \mathrm{C}$ até o momento de as larvas $\mathrm{L}_{3}$ serem analisadas. Todo o conteúdo foi examinado com auxílio de microscópio óptico, para contagem e identificação das larvas $\mathrm{L}_{3}$, de acordo com as orientações de Keith (1953).

O número das diferentes larvas foi analisado após a transformação $\log (\mathrm{x}+10)$, pelo pacote estatístico SAS. A análise de variância, para verificar os efeitos dos tratamentos, número de rotação dos animais na pastagem, e suas interações, foi feita pelo procedimento GLM. As médias foram comparadas pelo teste de Tukey a 5\% de probabilidade. Os procedimentos correlação e componentes principais foram utilizados para realizar suas respectivas análises.

\section{Resultados e Discussão}

As quantidades de larvas $\mathrm{L}_{3}$ recuperadas, em ordem decrescente, independentemente dos sistemas de pastejo utilizados na entrada dos animais na pastagem de capim-tanzânia, foram: Haemonchus spp., Trichonstrongylus spp., Oesophagostomum spp., Strongyloides spp. e Cooperia spp. (Tabela 1).

Tabela 1. Médias do número de larvas $L_{3}$ por quilograma de matéria seca, em capim-tanzânia, nos diferentes manejos de pastejo, na entrada e saída dos animais ${ }^{(1)}$.

\begin{tabular}{|c|c|c|c|c|c|c|}
\hline \multirow[t]{2}{*}{ Larva } & \multicolumn{4}{|c|}{ Manejos de pastejo $^{(2)}$} & \multirow[t]{2}{*}{ Média geral } & \multirow[t]{2}{*}{ Desvio-padrão } \\
\hline & Alternado & Bovinos & Ovinos & Simultâneo & & \\
\hline \multicolumn{7}{|c|}{ Entrada } \\
\hline Haemonchus spp. & $89,02 \mathrm{a}$ & $44,22 b c$ & $82,48 \mathrm{ab}$ & $40,15 c$ & 63,96 & 63,74 \\
\hline Trichostrongylus spp. & 14,14 & 16,50 & 20,47 & 9,09 & 15,05 & 19,69 \\
\hline Oesophagostomum spp. & 10,47 & 6,10 & 4,33 & 16,38 & 9,32 & 16,57 \\
\hline Strongyloides spp. & 8,22 & 6,23 & 7,65 & 0,00 & 5,52 & 10,25 \\
\hline Cooperia spp. & 1,54 & 10,46 & 0,00 & 6,65 & 4,66 & 15,25 \\
\hline Total & $123,39 \mathrm{a}$ & $83,51 \mathrm{bc}$ & $114,93 \mathrm{ab}$ & $72,27 \mathrm{c}$ & 98,52 & 86,83 \\
\hline \multicolumn{7}{|c|}{ Saída } \\
\hline Haemonchus spp. & 112,85 & 85,10 & 79,80 & 80,25 & 89,50 & 73,58 \\
\hline Trichostrongylus spp. & 21,46 & 24,79 & 18,31 & 13,56 & 19,53 & 21,38 \\
\hline Oesophagostomum spp. & 9,77 & 12,56 & 6,36 & 10,25 & 9,73 & 18,48 \\
\hline Cooperia spp. & $16,95 \mathrm{ab}$ & $21,09 \mathrm{ab}$ & $6,18 b$ & $16,24 \mathrm{ab}$ & 15,11 & 17,64 \\
\hline Strongyloides spp. & $11,65 \mathrm{a}$ & $1,34 \mathrm{~b}$ & $5,30 \mathrm{ab}$ & $3,26 \mathrm{~b}$ & 5,39 & 12,28 \\
\hline Total & 172,68 & 144,38 & 115,95 & 123,56 & 139,14 & 98,84 \\
\hline
\end{tabular}


Comportamento semelhante também foi observado na saída, com exceção de Cooperia spp., que superou as larvas de Oesophagostomum spp. e Strongyloides spp. As espécies encontradas são semelhantes às descritas em outros trabalhos realizados na região (Veloso et al., 2004; Cenci et al., 2007), bem como no Norte (Braga \& Girardi, 1991), Sudeste (Graminha et al., 2005) e Sul do Brasil (Pegoraro et al., 2008). Segundo Borba et al. (1993), em rebanho de ovinos, apenas uma parcela da população parasitária (menos de 5\%) encontra-se dentro dos animais, enquanto os $95 \%$ restantes encontram-se nas pastagens.

As larvas $\mathrm{L}_{3}$ de Haemonchus spp. foram encontradas em maior quantidade e foram as que apresentaram diferenças significativas entre os tratamentos, com menor valor na pastagem do manejo simultâneo, em comparação às dos manejos ovinos e alternado (Tabela 1). Este parasito é responsável pela ocorrência de anemia grave em ruminantes, pois ocasiona a morte dos animais, principalmente em ovinos. Vários levantamentos epidemiológicos têm demonstrado ser este o verme que compõe a maior parte da carga parasitária dos animais, na região Sudeste do Brasil (Amarante et al., 2004). Em condições tropicais, o mesmo resultado foi encontrado, na Etiópia, por Sissay et al. (2007), em que a hemoncose e a tricostrongilose (Trichostrongylus axei e T. colubriformis) foram as duas verminoses de maior ocorrência. Niezen et al. (1998) observaram que a espécie da forrageira pode ter um impacto significativo na dinâmica populacional e na migração de larvas de T. colubriformis e Ostertagia circumcincta.

As médias das larvas $\mathrm{L}_{3}$ de nematódeos encontrados na entrada dos animais nos piquetes foram maiores nos pastejos alternado e isolado de ovinos para o Haemonchus spp. (Tabela 1). O resultado para o pastejo alternado está de acordo com o encontrado por Fernandes et al. (2004). Em condições favoráveis, as larvas infectantes podem sobreviver durante várias semanas ou até vários meses no ambiente (Souza et al., 2000; Rocha, 2006; Carneiro \& Amarante, 2008).

Existe maior diversidade entre as espécies de nematódeos, quando os ovinos compartilham a pastagem com bovinos (Giudici et al., 1999). No entanto, esta observação não foi confirmada pelos resultados do presente trabalho. Isto pode ser justificado pelo fato de a área da pastagem ter sido recém-implantada, sem a presença de animais e, também, porque os animais passaram por vermifugação e só entraram nos piquetes após verificada a ausência de ovos nas fezes por OPG. As espécies encontradas são aquelas que mais acometem os ovinos e bovinos e as que têm maior potencial biótico.

As médias das larvas $\mathrm{L}_{3}$, na entrada dos animais no pasto, foram comparadas ao número de rotações dos animais no mesmo piquete, tendo-se observado que Haemonchus spp. esteve presente desde o início e que, a partir da segunda rodada, todas as outras espécies estudadas foram encontradas no pasto (Tabela 2). Amarante et al. (2004) e Ramos et al. (2004) apontam que a importância relativa das diferentes espécies varia em razão da combinação de três fatores: intensidade da infecção, prevalência e patogenicidade do parasito. Quando comparadas as médias das larvas, nos ciclos referentes às saídas dos animais da pastagem, verificou-se que houve aumento gradativo em todas as espécies, quando o número de rotações dos animais foi maior, com exceção da espécie Strongyloides. Na diferença entre o número das larvas de saída e o das larvas de entrada, houve diferença significativa para as espécies de Strongyloides e Cooperia e, para ambas, ocorreu decréscimo no quarto ciclo (Tabela 2). A ocorrência de aumento de $\mathrm{L}_{3}$ de determinada espécie na pastagem, seguida da diminuição da mesma espécie, pode ter sido influenciada pelas condições climáticas. De acordo

Tabela 2. Médias do número de larvas $\mathrm{L}_{3}$ por quilograma de matéria seca, em pastagem de capim-tanzânia, na entrada, na saída e da diferença entre a saída e a entrada dos animais no pasto, nos ciclos de pastejo crescentes ${ }^{(1)}$.

\begin{tabular}{|c|c|c|c|c|c|c|c|c|c|c|c|c|}
\hline \multirow[t]{2}{*}{ Larva } & \multicolumn{4}{|c|}{ Entrada } & \multicolumn{4}{|c|}{ Saída } & \multicolumn{4}{|c|}{ Diferença (saída e a entrada) } \\
\hline & $1^{\circ}$ Ciclo & $2^{-}$Ciclo & $3^{\circ}$ Ciclo & $4^{\circ}$ Ciclo & $1^{\circ}$ Ciclo & $2^{\circ}$ Ciclo & $3^{\circ}$ Ciclo & $4^{\circ}$ Ciclo & $1^{\circ}$ Ciclo & $2^{\circ}$ Ciclo & $3^{\circ}$ Ciclo & $4^{\circ}$ Ciclo \\
\hline Haemonchus spp. & $4,56 \mathrm{~b}$ & $61,06 \mathrm{~b}$ & $104,94 \mathrm{ab}$ & $128,59 a$ & $36,31 \mathrm{c}$ & $89,60 \mathrm{~b}$ & $105,81 \mathrm{a}$ & $119,70 \mathrm{a}$ & 31,75 & 28,24 & 0,87 & $-8,89$ \\
\hline Trichostrongylus spp. & $0,00 \mathrm{c}$ & $10,58 \mathrm{bc}$ & $30,16 \mathrm{a}$ & $27,41 \mathrm{ab}$ & $1,51 \mathrm{~b}$ & $14,88 \mathrm{ab}$ & $33,29 a$ & $27,92 a$ & 1,51 & 4,29 & 3,14 & 0,52 \\
\hline Oesophagostomum spp. & $0,00 \mathrm{~b}$ & $8,02 \mathrm{ab}$ & $21,54 \mathrm{a}$ & $4,92 \mathrm{~b}$ & 2,33 & 11,59 & 16,04 & 8,98 & 2,33 & 3,57 & $-5,5$ & 4,07 \\
\hline Cooperia spp. & $0,00 \mathrm{~b}$ & $2,62 \mathrm{ab}$ & $6,82 \mathrm{ab}$ & $17,08 \mathrm{a}$ & $0,00 \mathrm{~b}$ & $14,16 \mathrm{~b}$ & $18,85 \mathrm{ab}$ & $26,95 \mathrm{a}$ & $0,00 \mathrm{~b}$ & $11,54 \mathrm{ab}$ & $12,06 \mathrm{a}$ & $9,89 \mathrm{~b}$ \\
\hline Strongyloides spp. & $0,00 \mathrm{~b}$ & 7,94ab & $5,66 \mathrm{ab}$ & $14,42 \mathrm{a}$ & $0,00 \mathrm{~b}$ & $5,48 \mathrm{ab}$ & $14,31 \mathrm{a}$ & $0,00 \mathrm{~b}$ & $0,00 \mathrm{ab}$ & $-2,46 b$ & $8,65 a$ & $-14,42 \mathrm{c}$ \\
\hline
\end{tabular}

${ }^{(1)}$ Médias seguidas de letras iguais, nas linhas, não diferem entre si pelo teste de Tukey, a 5\% de probabilidade. 
com Sciacca et al. (2002), um período muito chuvoso pode fazer com que as larvas migrem em condições erráticas para a base da forrageira. Santos et al. (2002) afirmaram que parte da área de solo descoberto, entre as touceiras, pode favorecer a penetração de raios solares e ventos, o que promove a redução da umidade no microclima da pastagem e altera o comportamento das larvas infectantes.

Em geral, as correlações entre a contagem de larvas, na entrada e saída dos animais, e o número de rotações na pastagem foram médias e positivas, o que indica que quanto mais vezes os animais entraram e saíram do pasto, mais alta foi a contaminação (Tabela 3). As correlações da rotação com a diferença entre as contagens de larvas, na entrada e saída, foram baixas e não significativas, o que indica que a rotação não afetou esta diferença.

As correlações entre as entradas e saídas foram de médias a baixas, tanto com o mesmo gênero de larva, quanto entre gêneros diferentes larvas, e as correlações mais altas foram observadas na entrada e saída em Haemonchus spp. com gêneros diferentes de entrada e saída em Trichostrongylus spp. e Strongyloides spp.

$\mathrm{Na}$ maioria dos parasitos encontrados, a quantidade de larvas na entrada dos animais foi negativamente correlacionada à diferença entre as quantidades de lavras de mesmo gênero na entrada e saída dos animais. Isto significa que, quando a quantidade na entrada foi alta, houve um pequeno aumento na quantidade de saída, e vice-versa. Nessa situação, o que pode ter ocorrido foi que os animais consumiram as larvas, pela grande disponibilidade delas, ou não houve tempo de os ovos depositados na pastagem evoluírem para o estágio de larvas infectantes, o que significa que a maioria das larvas ainda estava no estágio $\mathrm{L}_{1}$ e $\mathrm{L}_{2}$ (larvas de vida livre).
Os dois autovetores apresentados na Figura 1 permitiram explicar $40 \%$ de toda a variação na ocorrência de $\mathrm{L}_{3}$ no experimento. $\mathrm{O}$ autovetor 1 mostrou que, com o aumento do número de ciclos de pastejo, aumentou o número de larvas $\mathrm{L}_{3}$, tanto na entrada quanto na saída dos animais, em todos os tratamentos. As diferenças no número das larvas $L_{3}$ entre a saída e entrada dos animais também aumentaram, principalmente aquelas entre o número de larvas de Cooperia spp., enquanto as do número de Haemonchus spp. e de Oesophagostomum spp. diminuíram um pouco. $\mathrm{O}$ autovetor 2 mostrou que, quando a quantidade de larvas na entrada foi baixa, as diferenças entre a saída e entrada foram altas em Trichostrongylus spp., Cooperia spp. e Oesophagostomum spp., mas, apesar de a diferença ter sido alta, essas espécies aparecem em menor quantidade, em relação a Haemonchus spp. Mesmo em menor quantidade e com patogenia mais leve, essas espécies não devem ser negligenciadas, pois, normalmente, o que ocorre em campo são infecções mistas, que potencializam os seus efeitos indesejáveis.

Nos diferentes sistemas de manejo, a espécie predominante foi Haemonchus spp., com $64,32 \%$, pois, segundo Romero \& Boero (2001), a oviposição diária dessa espécie varia de 5.000 a 10.000 ovos, e é muito superior à de Trichostrongylus spp. que é de apenas 100 a 200 ovos por dia. Esta última espécie ocupou o segundo lugar, com $14,65 \%$ da larvas. Nos tratamentos em que havia as duas espécies de ruminantes, as larvas de Haemonchus spp. estavam divididas entre H. placei e H. contortus, que acometem bovinos e ovinos especificamente. Assim, a possibilidade de infecção ficou reduzida, em relação aos tratamentos

Tabela 3. Matriz de correlação das quantidades de larvas $\mathrm{L}_{3}$ contadas na saídas (S) e na entrada (CE) dos animais no pasto, e da diferença entre esses valores (Dif), e o número de rotações utilizadas ${ }^{(1)}$.

\begin{tabular}{|c|c|c|c|c|c|c|c|c|c|c|c|c|c|c|c|}
\hline & E-Tri & E-Str & E-Hae & E-Coo & E-Oes & S-Tri & S-Str & S-Hae & S-Coo & S-Oes & Dif-Tri & Dif-Str & Dif-Hae & Dif-Coo & Dif-Oes \\
\hline E-Str & $0,22^{*}$ & & & & & & & & & & & & & & \\
\hline E-Hae & $0,44 * * *$ & $0,55^{* * *}$ & & & & & & & & & & & & & \\
\hline E-Coo & 0,21 & 0,07 & 0,00 & & & & & & & & & & & & \\
\hline E-Oes & $0,32 * *$ & 0,16 & 0,19 & 0,17 & & & & & & & & & & & \\
\hline S-Tri & $0,38 * *$ & $0,25^{*}$ & $0,41 * *$ & 0,22 & 0,17 & & & & & & & & & & \\
\hline S-Str & 0,18 & $0,29^{*}$ & $0,46^{* *}$ & 0,17 & 0,22 & $0,35^{* * *}$ & & & & & & & & & \\
\hline S-Hae & 0,11 & $0,31^{*}$ & $0,39 * *$ & $-0,05$ & 0,06 & $0,28^{*}$ & $0,31 *$ & & & & & & & & \\
\hline S-Coo & 0,15 & $0,27^{*}$ & $0,39 * *$ & $0,50 * *$ & $0,32 *$ & $0,28 *$ & $0,25 *$ & 0,13 & & & & & & & \\
\hline S-Oes & 0,01 & 0,00 & 0,18 & $-0,09$ & 0,10 & 0,06 & 0,16 & 0,18 & $0,30 * *$ & & & & & & \\
\hline Dif-Tri & $-0,51 * * *$ & 0,00 & 0,05 & 0,00 & $-0,07$ & $0,61 * * *$ & 0,17 & 0,17 & 0,14 & 0,05 & & & & & \\
\hline Dif-Str & $-0,04$ & $-0,49 * * *$ & 0,03 & 0,11 & 0,07 & 0,13 & $0,69 * * *$ & 0,04 & 0,02 & 0,15 & 0,16 & & & & \\
\hline Dif-Hae & $-0,22$ & $-0,13$ & $-0,46$ & $-0,03$ & $-0,06$ & $-0,07$ & $-0,09$ & $0,64 * * *$ & $-0,19$ & 0,02 & 0,12 & 0,02 & & & \\
\hline Dif-Coo & $-0,06$ & $0,24 *$ & $0,43 * * *$ & $-0,39 * *$ & 0,23 & 0,10 & 0,11 & 0,19 & $0,60 * * *$ & $0,40 * *$ & 0,14 & $-0,08$ & $-0,18$ & & \\
\hline Dif-Oes & $-0,18$ & $-0,12$ & 0,04 & $-0,16$ & $-0,62 * * *$ & $-0,07$ & $-0,03$ & 0,10 & 0,01 & $0,71 * * *$ & 0,08 & 0,06 & 0,06 & 0,15 & \\
\hline Rotação & $0,55 * * *$ & $0,33 * *$ & $0,65 * * *$ & 0,32 & $0,33 * *$ & $0,57 * * *$ & $0,33 * *$ & $0,40 * *$ & $0,48 * *$ & $0,25 *$ & 0,03 & 0,12 & $-0,12$ & 0,15 & $-0,09$ \\
\hline
\end{tabular}

${ }^{(1)}$ Str, Strongyloides spp.; Hae, Haemonchus spp.; Tri, Trichostrongylus spp.; Coo, Cooperia spp.; Oes, Oesophagostumum spp.; E, entrada; S, saída; Dif, diferença na contagem de $\mathrm{L}_{3}$ entre a saída e a entrada dos animais nos pastos. *, ** e ***Significativo a 5,1 e $0,1 \%$ de probabilidade, respectivamente. 


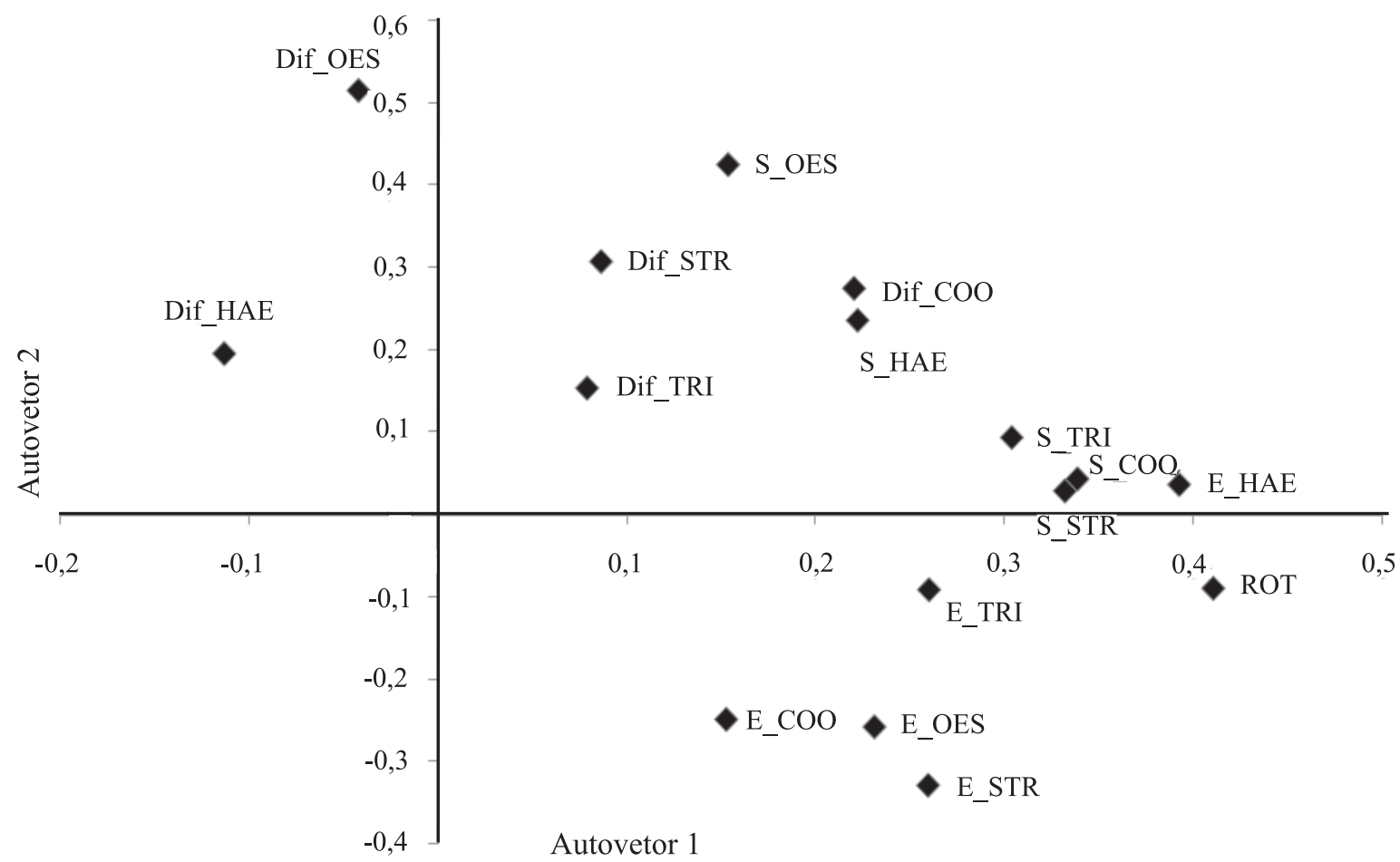

Figura 1. Os dois primeiros autovetores da ocorrência de larvas $\mathrm{L}_{3}$ em pastagens de capim-tanzânia. STR, Strongyloides spp.; HAE, Haemonchus spp.; Tri, Trichostrongylus spp.; COO, Cooperia spp.; OES, Oesophagostomun spp.; E, entrada dos animais nos pastos; S, saída dos animais dos pastos; Dif, diferença na contagem de lavras $\mathrm{L}_{3}$ entre a saída e a entrada dos animais nos pastos.

que apresentavam apenas uma espécie de ruminante, pois as larvas presentes, neste caso, seriam da própria espécie hospedeira. Quanto aos manejos alternado e simultâneo, este último teve a menor contaminação na entrada dos animais e apresentou vantagens sobre o alternado por necessitar de menor quantidade de piquetes e por ter redução de mão de obra, pela condução de apenas um único grupo de animais.

\section{Conclusão}

O pastejo simultâneo de bovinos e ovinos proporciona melhor controle da carga parasitária de Haemonchus spp., em pastagem de capim-tanzânia.

\section{Agradecimentos}

À Coordenação de Aperfeiçoamento de Pessoal de Nível Superior, ao Conselho Nacional de Pesquisa, à Fundação de Apoio à Pesquisa do Distrito Federal e à Fundação de Empreendimentos Científicos e Tecnológicos, pelo auxílio financeiro.

\section{Referências}

AMARANTE, A.F.T. Controle de endoparasitoses dos ovinos. In: REUNIÃO ANUAL DA SOCIEDADE BRASILEIRA DE ZOOTECNIA, 38., 2001, Piracicaba. Anais. Brasília: Sociedade Brasileira de Zootecnia; Piracicaba: FEALQ, 2001. p.461-471.

AMARANTE, A.F.T.; BRICARELLO, P.A.; ROCHA, R.A.; GENNARI, S.M. Resistance of Santa Ines, Suffolk and Ile de France sheep to naturally acquired gastrointestinal nematode infections. Veterinary Parasitology, v.120, p.91-106, 2004.

BORBA, M.F.S.; MORNES, J.C.F.; SILVEIRA, V.C.P. Aspectos relativos à produção de carne ovina. In: SIMPÓSIO PARANAENSE DE OVINOCUlTURA, 6., 1993, Maringá. Anais. Maringá: CRMVZ, 1993. p.15-26.

BRAGA, R.M.; GIRARDI, J.L. População de larvas de helmintos infestantes de ovinos em pastagem nativa de Roraima. Pesquisa Agropecuária Brasileira, v.26, p.569-574, 1991.

CARNEIRO, R.D.; AMARANTE, A.F.T. Seasonal effect of three pasture plants species on the free-living stages of Haemonchus contortus. Arquivo Brasileiro de Medicina Veterinária e Zootecnia, v.60, p.864-872, 2008.

CARVALHO, P.C.F.; RODRIGUES, L.R.A. Potencial de exploração integrada de bovinos e outras espécies para utilização 
intensiva de pastagens. In: SIMPÓSIO SOBRE O MANEJO DA PASTAGEM, 13., 1996, Piracicaba. Anais. Piracicaba: FEALQ, 1997. p.115-128.

CENCI, F.B.; LOUVANDINI, H.; MCMANUS, C.M.; DELL' PORTO, A.; COSTA, D.M.; ARAUJO, S.C.; MINHO, A.P.; ABDALLA, A.L. Effects of condensed tannin from Acacia mearnsii on sheep infected naturally with gastrointestinal helminthes. Veterinary Parasitology, v.144, p.132-137, 2007.

FERNANDES, L.H.; SENO, M.C.Z.; AMARANTE, A.F.T.; SOUZA, H.; BELLUZZO, C.E.C. Efeito do pastejo rotacionado e alternado com bovinos adultos no controle da verminose em ovelhas. Arquivo Brasileiro de Medicina Veterinária e Zootecnia, v.56, p.733-740, 2004.

GIUDICI, C.; AUMONT, G.; MAHIEU, M.; SAULAI, M.; CABARET, J. Changes in gastro-intestinal helminth species diversity in lambs under mixed grazing on irrigated pastures in the tropics (French West Indies). Veterinary Research, v.30, p.573-581, 1999.

GRAMINHA, É.B.N.; MONTEIRO, A.C.; SILVA, H.C. da; OLIVEIRA, G.P.; COSTA, A.J. da. Controle de nematóides parasitos gastrintestinais por Arthrobotrys musiformis em ovinos naturalmente infestados mantidos em pastagens. Pesquisa Agropecuária Brasiliera, v.40, p.927-933, 2005.

JACKSON, F.; COOP, R.L. The development of anthelmintic resistance in sheep nematodes. Parasitology, v.120, p.95-107, 2000.

KAPLAN, R.M. Drug resistance in nematodes of veterinary importance: a status report. Trends in Parasitology, v.20, p.477-481, 2004.

KEITH, R.K. The differentiation of the infective larvae of some common nematode parasites of cattle. Australian Journal of Zoology, v.1, p.223-225, 1953.

LOUVANDINI, H.; VELOSO, C.F.M.; PALUDO, G.R.; DELL' PORTO, A.; GENNARI, S.M.; MCMANUS, C.M. Influence of protein supplementation on the resistance and resilience on young hair sheep naturally infected with gastrointestinal nematodes during rainy and dry seasons. Veterinary Parasitology, v.137, p.103-111, 2006.

MILLER, J.E.; HOROHOV, D.W. Immunological aspects of nematode parasite control in sheep. Journal of Animal Science, v.84, p.124-132, 2006.

NIEZEN, J.H.; CHARLESTON, W.A.G.; HODGSON, J.; MILLER, C.M.; WAGHORN, T.S.; ROBERTSON, H.A. Effect of plant species on the larvae of gastrointestinal nematodes which parasitise sheep. International Journal for Parasitology, v.28, p.791-803, 1998.

PEGORARO, E.J.; POLI, C.H.E.C.; CARVALHO, P.C. de F.; GOMES, M.J.T. de M.; FISCHER, V. Manejo da pastagem de azevém, contaminação larval no pasto e infecção parasitária em ovinos. Pesquisa Agropecuária Brasileira, v.43, p.1397-1403, 2008.

RAMOS, C.I.; BELLATO, V.; SOUZA, A.P. de; AVILA, V.S. de; COUTINHO, G.C.; DALAGNOL, C.A. Epidemiologia das helmintoses gastrintestinais de ovinos no Planalto Catarinense. Ciência Rural, v.34, p.1889-1895, 2004.

ROCHA, R.A. da; PACHECO, R.D.L.; AMARANTE, A.F.T. Efficacy of homeopathic treatment against natural infection of sheep by gastrointestinal nematodes. Revista Brasileira de Parasitologia Veterinária, v.15, p.23-27, 2006.

ROMERO, J.R.; BOERO, C.A. Epidemiología de la gastroenteritis verminosa de los ovinos en las regiones templadas y cálidas de la Argentina. Analecta Veterinaria, v.21, p.21-37, 2001.

SANTOS, L.E.; BUENO, M.S.; CUNHA, E.A.; VERÍSSIMO C.J. Manejo de pastagens para a produção de ovinos. In: SIMPÓSIO MINEIRO DE OVINOCULTURA, 2., 2002, Lavras. Anais. Lavras: UFLA, 2002. p.105-140.

SCIACCA, J.; FORBES, W.M.; ASHTON, F.T.; LOMBARDINI, E.; GAMBLE, H.R.; SCHAD, G.A. Response to carbon dioxide by the infective larvae of three species of parasitic nematodes. Parasitology International, v.51, p.53-62, 2002.

SISSAY, M.M.; UGGLA, A.; WALLER, P.J. Epidemiology and seasonal dynamics of gastrointestinal nematode infections of sheep in a semi-arid region of Eastern Ethiopia. Veterinary Parasitology, v.143, p.311-321, 2007.

SOUZA, P. de; BELATO V.; SARTOR, A.A.; RAMOS, C.I. Período para desinfestação das pastagens por larvas nematóides gastrintestinais de ovinos, em condições naturais nos campos de Lages, SC. Revista Brasileira de Parasitologia Veterinária, v.9, p.159-164, 2000.

VELOSO, C. de F.M.; LOUVANDINI, H.; KIMURA, E.A.; AZEVEDO C.R.; ENOKI, D.R. de; FRANÇA, L.D. de; MCMANUS, C.M.; DELL' PORTO, A.; SANTANA, A.P. Efeitos da suplementação protéica no controle da verminose e nas características de carcaça de ovinos Santa Inês. Ciência Animal Brasileira, v.5, p.131-139, 2004.

Recebido em 17 de outubro de 2008 e aprovado em 31 de junho de 2009 